\title{
SERUM SOLUBLE ADHESION MOLECULES (sICAM-1, sVCAM-1, sE-SELECTIN) AND NEOPTERIN IN PATIENTS WITH SJÖGREN'S SYNDROME
}

\author{
Ctirad Andrýs ${ }^{1}$, Jan Krejsek ${ }^{2}$, Radovan Slezák $k^{3}$, Marcela Drahošová ${ }^{1}$, Otakar Kopecký2
}

University Teaching Hospital in Hradec Králové: Department of Clinical Immunology and Allergology1; Charles University in Prague, Faculty of Medicine in Hradec Králové: Department of Clinical Immunology and Allergology ${ }^{2}$, Department of Dentistry 3

\begin{abstract}
Summary: Sjögren's syndrome is a systemic autoimmune disease characterized by focal lymphocytic infiltration of the salivary and lacrimal glands. Expression and up-regulation of adhesion molecules and activation of cellular immune system is essential for the migration of inflammatory cells into tissues. Soluble forms of adhesion molecules sICAM-1, sVCAM-1, sE-selectin and neopterin were analyzed in serum of 17 patients with primary Sjögren's syndrome and 11 patients with secondary Sjögren's syndrome together with 26 age-matched healthy blood donors. There were significantly higher serum concentrations (mean $\pm 1 \mathrm{SD})$ of sICAM-1 $(362.0 \pm 67.9 \mathrm{ng} / \mathrm{ml}, \mathrm{p}<0.001)$, sE-selectin $(78.7 \pm 28.1 \mathrm{ng} / \mathrm{ml}, \mathrm{p}<0.001)$ and neopterin $(17.9 \pm 6.4 \mathrm{nmol} / \mathrm{l}, \mathrm{p}<0.001)$ in primary Sjögren's syndrome patients in comparison to control group (sICAM-1: $128.3 \pm 46.9 \mathrm{ng} / \mathrm{ml}$, sE-selectin : $46.3 \pm 39.5 \mathrm{ng} / \mathrm{ml}$, and neopterin : $7.6 \pm 2.3 \mathrm{nmol} / 1)$. Sera from patients with secondary Sjögren's disease contained significantly higher levels of sICAM-1 (356.0 $\pm 62.4 \mathrm{ng} / \mathrm{ml}, \mathrm{p}<0.001)$, sE-selectin $(65.5 \pm 27.0 \mathrm{ng} / \mathrm{ml}, \mathrm{p}<0.05)$, and neopterin $(18.8 \pm 9.8 \mathrm{nmol} / 1, \mathrm{p}<0.001)$ in comparison with control group. There were no significant differences between patients with primary and secondary Sjögren's syndrome in any parameters tested. No statistically significant differences in serum levels of sVCAM-1 were found either in patients with primary or secondary SS compared to control group.
\end{abstract}

Key words: Neopterin; sE-selectin; sICAM-1; Sjögren's syndrome; sVCAM-1

\section{Introduction}

Sjögren's syndrome (SS) is a chronic autoimmune disease characterized by a progressive lymphocytic and plasma cell infiltration of the salivary and lacrimal glands leading to the xerostomia and xerophthalmia (sicca complex) (1,19,35). $\mathrm{SS}$ is associated with the production of rheumatoid factors (RF) and a variety of antinuclear autoantibodies among them autoantibodies against SS-A/Ro and SS-B/La are the most important. SS displays a broad clinical spectrum extending from autoimmune exocrinopathy to the extraglandular (systemic) disease affecting the lungs, kidneys, blood vessels and muscles. SS can occur alone (primary) or in association with other autoimmune diseases (secondary) (24).

The trapping of leukocytes from the blood stream and their subsequent rolling along the activated endothelial cell lining of postcapilary venules are the earliest signs of inflammation. Rolling is an essential element of the multistep cascade leading to the leukocyte recruitment into sites of inflammation. It is mediated by the interactions between E-selectins on the surface of activated endothelial cells and their ligands, which are heavily glycosylated surface molecules of leukocytes e.g. CD15 molecule of granulocytes.
Granulocytes, monocytes and a subset of memory T cells could be bound through this interaction. Next step is mediated through the interaction between adhesion molecules belonging into the families of immunoglobulins and integrins. ICAM-1 will bind cells expressing the beta 2 integrins, including lymphocytes, granulocytes, and monocytes. VCAM-1 will bind only those cells expressing the beta1 integrin VLA-4; lymphocytes, eosinophils, basophils, and monocytes $(11,16,21,37)$.

Membrane adhesion molecules are shed into the body fluids by the proteolytic cleavage or by alternative splicing on the level of mRNA (15). The elevated levels of soluble adhesion molecules are found in the serum of patients with various inflammatory diseases, and may provide some useful diagnostic or prognostic informations (14).

Neopterin is produced by macrophages after activation with interferon gamma, a cytokine produced by CD4+ helper-inducer lymphocytes. Increased neopterin concentration thus reflects the activation of specific cellular immunity. An elevation of serum or urine neopterin levels has been proven in autoimmune disorders including rheumatoid arthritis, systemic lupus erythematosus, inflammatory bowel disease, or sarcoidosis $(13,39)$. 
We found significantly higher serum levels of neopterin, sICAM-1, and sE-selectin in patients with both primary and secondary SS in comparison with healthy controls in this study.

\section{Material and methods}

\section{Patients}

This study was approved by the Ethical Committee of Charles University School of Medicine, Hradec Králové. Informed consent of all participants was obtained.

The serum samples were drawn from 17 patients ( $15 \mathrm{fe}$ males, 2 males, average age 58 years, range $41-79$ years) with primary SS and 11 patients with secondary SS (11 females, average age 64 , range $47-81$ years). All patients met criteria for the classification of SS according to Vitali et al. (38). The age-matched control group consists of 26 healthy female blood donors.

\section{Blood sampling}

Peripheral blood samples were collected by venipuncture into sterile tube (Sarstedt, Nuremberg, Germany). Samples were left for 1.5 hours at room temperature. Serum samples were stored frozen at $-20 \mathrm{oC}$ and thawed only once immediately before processing.

\section{Measurement of adhesion molecules}

Serum concentrations of sICAM-1, sVCAM-1 and sEselectin were obtained by use commercial ELISA kits Parameter Human Soluble ICAM-1, Parameter Human Soluble VCAM-1 and Parameter Human Soluble E-Selectin manufactured by RD Systems, Minneapolis, MN, USA. Serum levels of neopterin was measured by ELISA using a commercial kit (IBL, Germany). All ELISA techniques were performed according to the manufacturer's instructions. All measurement were done with the same batch, and in a duplicate.

\section{Statistical analysis}

The analysis was done using SigmaStat 2.0 statistical software Jandel Corporation, USA. The data were tested for normality. The differences between groups were calculated by t-test or Mann-Whitney Rank Sum test.

\section{Results}

sICAM-1: Statistically significant differences $(p<0.001)$ in the levels of serum sICAM-1 were found in both groups of SS patients with primary SS $(362.0 \pm 67.9 \mathrm{ng} / \mathrm{ml})$ and secondary SS $(356.0 \pm 62.4 \mathrm{ng} / \mathrm{ml})$ in comparison with controls (128.3 $\pm 46.9 \mathrm{ng} / \mathrm{ml})$ (Fig. 1.).

sE-selectin: Serum levels of sE-selectin were significantly elevated in patients with primary SS $(78.8 \pm 28.1 \mathrm{ng} / \mathrm{ml}$, $\mathrm{p}<0.001)$ in comparison with controls $(46.3 \pm 39.5 \mathrm{ng} / \mathrm{ml})$ as well as significant increase in concentrations of sE-selectin was observed in patients with secondary SS $(65.5 \pm 27.1$ $\mathrm{ng} / \mathrm{ml}, \mathrm{p}<0.05$ ) in comparison to the control group (Fig. 4.).
sVCAM-1: No statistically significant differences in serum levels of sVCAM-1 were found either in patients with primary or secondary SS compared to control group (Fig. 3.).

neopterin: Sera from patients with primary SS contained more neopterin $(17.9 \pm 6.4 \mathrm{nmol} / \mathrm{l}, \mathrm{p}<0.001)$ than control group $(7.6 \pm 2.3 \mathrm{nmol} / \mathrm{l})$. There were also significant differences in serum levels of neopterin between patients with secondary SS and control group (18.8 $\pm 9.8 \mathrm{nmol} / \mathrm{l}$ ) (Fig. 2.).

There were no significant differences between groups of patients with primary and secondary SS in any parameter tested.

Highly significant correlations were observed in patients with SS: between serum levels of neopterin and sICAM-1 (coefficient of correlation $\mathrm{r}=0.620, \mathrm{p}<0.001$, Figure 5.), between serum levels of sICAM-1 and sVCAM$1(\mathrm{r}=0.569, \mathrm{p}<0.001)$, and between sVCAM-1 and neopterin $(\mathrm{r}=0,599, \mathrm{p}=0.001)$, but not in control group (sICAM-1 $\mathrm{x}$ neopterin $\mathrm{r}=0.006, \mathrm{p}>0.05$; sICAM-1 x sVCAM-1 $\mathrm{r}=0.171$, $\mathrm{p}>0.05$; sVCAM-1 x neopterin $\mathrm{r}=0.035, \mathrm{p}>0.05$ ).

Fig. 1: Comparison of serum levels of sICAM-1 in primary SS, secondary SS and control group (dash lines deliminate the interval $5 \%$ - $95 \%$ percentiles of control group).

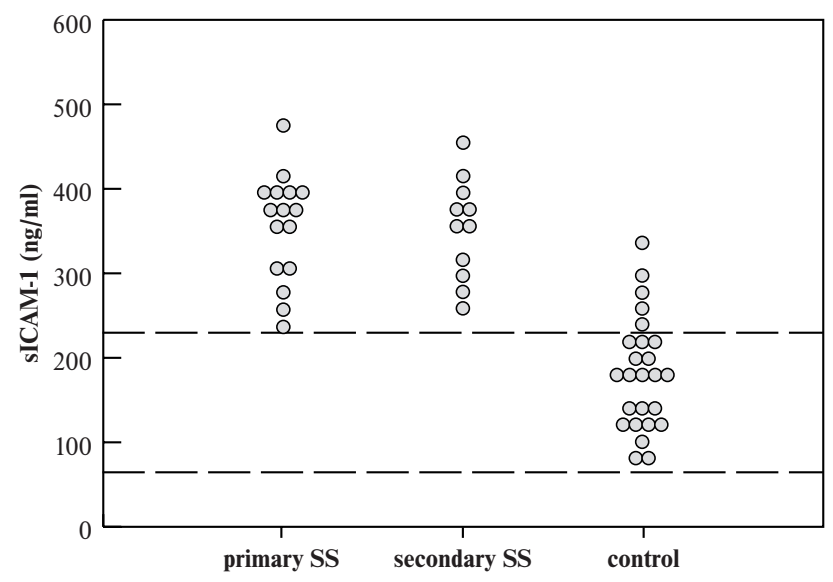

Fig. 2: Comparison of serum levels of neopterin in primary SS, secondary SS and control group (dash lines deliminate the interval $5 \%-95 \%$ percentiles of control group).

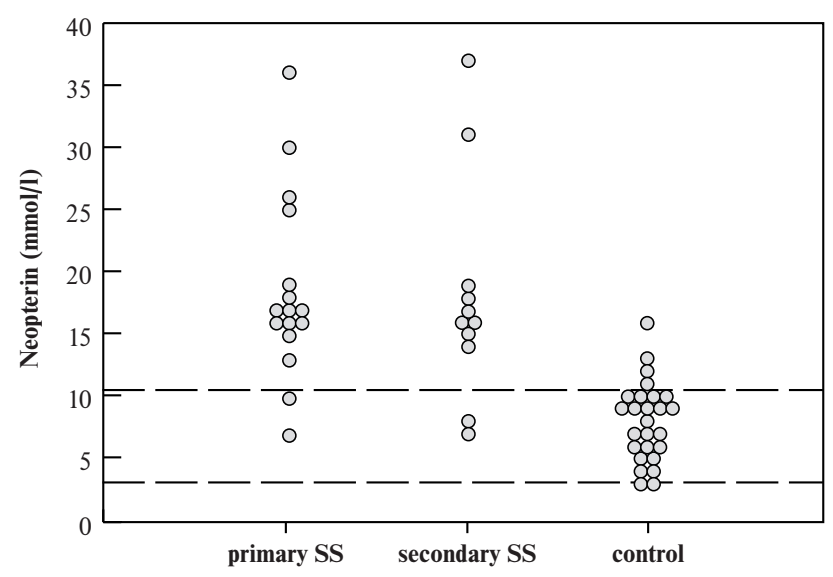


Fig. 3: Comparison of serum levels of sVCAM-1 in primary SS, secondary SS and control group (dash lines deliminate the interval 5\% - 95\% percentiles of control group).

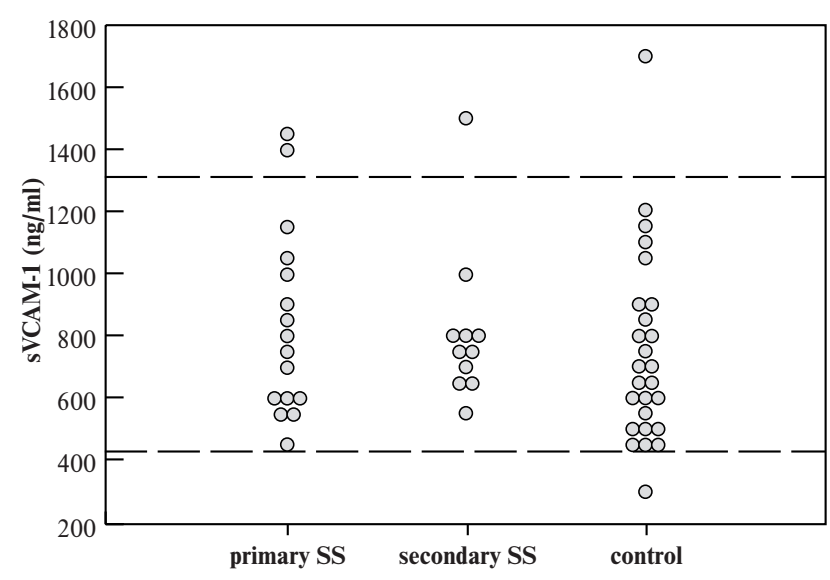

Fig. 4: Comparison of serum levels of sE-selectin in primary SS, secondary SS and control group (dash lines deliminate the interval $5 \%-95 \%$ percentiles of control group).

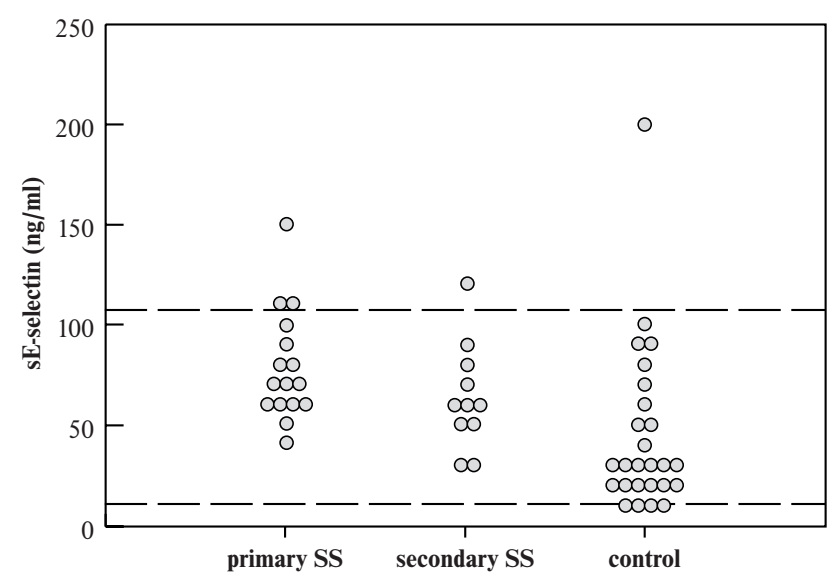

Fig. 5: Correlation between serum neopterin and sICAM-1 in group of patients with Sjögren's syndrome ( $r$ - coefficient of correlation.

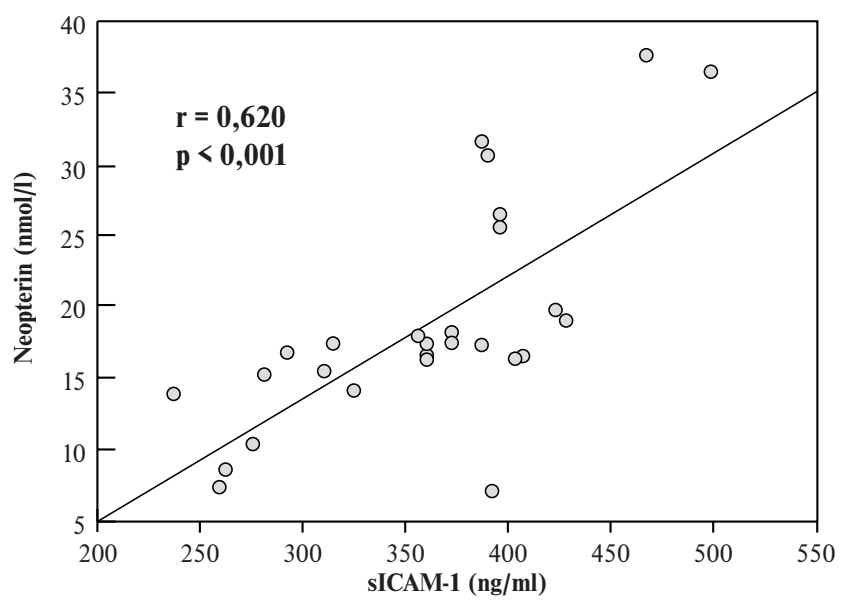

\section{Discussion}

Sjögren's syndrome is a chronic inflammatory disease of unknown origin marked by inflammation and destruction of the salivary and lacrimal glands. The impairment of salivary and lacrimal gland functions is caused by the destruction of acini and ductal cells accompanied by lymphocytic infiltration, which is believed to be immunologically mediated (35). CD4+CD45RO+ memory helper-inducer Tcells are the major subsets infiltrating the exocrine glands of Sjögren's syndrome patients. B cells subsequently appear in the lesions (2).

Leukocyte adhesion is a crucial step in the development of both normal immune response and inflammation $(7,16)$. Adhesion of leukocytes is mediated through the multiple interactions between adhesion molecules and their ligands. More recently we have learned that soluble isoforms of these adhesion structures can be found in the circulation and their levels can serve as a surrogate marker of disease activity $(14,32)$. The information obtained from measurement of soluble adhesion molecules can be interpreted at several different levels. The expression and subsequent release of soluble cellular adhesion molecules is mediated by proinflammatory stimuli both exogenous and endogenous origins such as endotoxin, histamin, thrombin, and various cytokines. Soluble cellular adhesion molecules may be regarded simply as markers of the presence and intensity of inflammation. The clinical utility of monitoring levels of soluble adhesion molecules is not yet established, but it is supposed that the availability of commercial assay kits should allow their evaluation in many clinical settings (15).

We found significantly elevated serum levels of sICAM-1, and sE-selectin in serum of both primary and secondary SS patients in comparison with healthy control. These findings could reflect hyperactivation of the immune system of SS patients which is well documented (35). The hallmarks of SS are hypergammaglobulinemia, presence of autoantibodies as the results of polyclonal activation of B cell system which is under the control of $\mathrm{T}$ cell. The putative autoantigen (or autoantigens) in salivary glands of SS patients has to be presented to $\mathrm{T}$ cells after binding to HLA class I or II molecules. These specific interactions that are accompanied by the costimulatory and accesory interactions lead to the production of cytokines upregulating the expression of adhesion molecules in affected tissues. It has to be stressed that there are numerous sources of such cytokines in salivary glands, including macrophages, epithelial and endothelial cells, T and B cells and fibroblasts. It could not be possible to distinguish among contributions of particular cell type from the serum levels of soluble adhesion molecules. Saito et al. $(30,31)$ reported that the expression of ICAM-1 in salivary glands of patients affected by SS is higher than in normal salivary gland. This upregulation of ICAM-1 correlated with the intensity of T cell infiltration, which are the only source of interferon gamma enhancing the expression of ICAM-1. Johanssen et al. (18) found hig- 
her levels of ICAM-1 in both serum and residual saliva of patients with primary SS in comparison with control. Recently, we have reported that serum levels of ICAM-1 is significantly higher in primary and secondary SS patients and in the case of secondary SS the level of SICAM-1 is correlated with the level of beta-2 microglobulin (20).

In comparison with ICAM-1 expression, the informations about another adhesion molecule, E-selectin, in SS are sparse. E-selectin is stored in intracellular granules of endothelial cells and it is expressed within minutes on their membranes after different stimuli including proinflammatory cytokines, products of blood coagulation, mechanical shear stress and many exogenous stimuli such as microbial products. E-selectin molecules mediate the rolling of activated granulocytes on the surface of activated endothelial cell lining through the interaction between $\mathrm{N}$-terminal end of E-selectin which is lectin-like and specific sugar residues on CD15 molecule of granulocytes (40). This seems to be not so much relevant for the pathogenesis of SS, because granulocytes play only a limited role in this disease. But E-selectin could mediate the binding of particular lymphocyte populations, for example skin-homing T cells (27) and memory $\mathrm{T}$ cells (33). Because the lymphoid infiltration of salivary glands in SS consists of predominantly helper $\mathrm{T}$ cells with memory phenotype (CD4+CD45RO+) one could speculate, that E-selectin is partially responsible for this accumulation, but Aziz and coworkers (3) has not found increased expression of E-selectin in salivary gland of SS patients. Their results are in agreement with the findings of Flipo and coworkers (12). The role of E-selectin in SS warrants further investigation.

Our findings that serum levels of E-selectin are increased in both primary and secondary SS patients in comparison with control may reflect overall activation of endothelial cells in these patients. The serum or plasma levels of E-selectin are reported to be elevated in patients with other immunopathological diseases for example atopic dermatitis and psoriasis (9), vasculitis and scleroderma (8), as well as in malignancies $(4,36)$, and in infectious complications such as septic shock (26). Spronk et al. (34) have not found elevation of serum E-selectin in patients with systemic lupus erythematosus and there was no correlation of sE-selectin with disease activity. Our results suggest that elevated serum levels of sE-selectin in primary and secondary SS are caused by the activation and probably destruction of endothelial cells $(5,6)$. This destruction is partially mediated by the autoantibodies against endothelial cells which are seen in SS patients (22). It is interesting that there is no difference in the level of E-selectin between primary and secondary SS patients.

The serum levels of sVCAM-1 were not elevated in SS patients in comparison with control in our study. VCAM-1 is expressed on the surface of activated endothelial cells and it is responsible together with ICAM-1 for the firm adhesion of leucocytes. There is a great difference in the action of VCAM-1 and ICAM-1. In the case of ICAM-1 all leucocytes could adhere through the LFA-1 beta2 integrin which is expressed on all leucocytes. In a sharp contrast, in the case of VCAM-1 the adherence of leucocytes is much more selective because VCAM-1 is a ligand for beta 1 integrin VLA-4. Enhanced expression of VCAM-1 on the endothelium may facilitate the transmigration of monocytes and CD4+ memory effector cells, since these cells express VLA-4, whereas ,naive“ CD4+ T cells do not (17).

Neopterin is an oxidation product of 7,8-dihydroneopterin which is synthesized from guanosine triphosphate (GTP) by the enzyme GTP cyclohydrolase I. The production of 7,8-dihydroneopterin represents a first step in the pathway leading to the synthesis of tetrahydrobiopterin, an enzyme cofactor. For some yet unknown reason the activity of GTP cyclohydrolase I is present in a great excess compared to the enzymes active distally in the tetrahydrobiopterin pathway in human macrophages after treatment with interferon gamma leading to a remarkable rise in 7,8-dihydroneopterin. 7,8-dihydroneopterin is in equilibrium with its oxidized form, neopterin, which can be monitored in body fluids $(23,29,39)$.

Increased concentration of neopterin in serum or in urine has been documented in many autoimmune disorders, including rheumatoid arthritis, systemic lupus erythematosus, sarcoidosis, or inflammatory bowel disease, and increased neopterin levels have been associated with disease activity $(10,25,28)$.

Numerous factors, genetical, infectious, immunological and environmental are thought to play a role in the pathogenesis of SS. Substantial progress has been made recently in the investigation of dysregulation of the immune system in SS patients. Our results support immunopathological etiology of this enigmatic disease.

\section{References}

1. Anaya JM, Ogawa N, Talal N. Sjögren's syndrome in childhood. J Rheumatol 1999;22:1152-8.

2. Andrade RE, Hagen KA, Manivel JC. Distribution and immunophenotype of the inflammatory cell population in the benign lymphoepithelial lesions (Mikulicze's disease). Hum Pathol 1988;19:932-40.

3. Aziz KE, McCluskey PJ, Wakefield D. Epithelial and endothelial cell expression of surface adhesion molecules and their ligands in labial salivary glands from patients with Sjögren's syndrome. Clin Rheumatol 1995;14:S1,44.

4. Banks RE, Gearing AJH, Hemingway IK, Norfolk DR, Perren TJ, Selby PJ. Circulating intercellular adhesion molecule-1 (ICAM-1), E-selectin and vascular cell adhesion molecule-1 (VCAM-1) in human malignancies. $\mathrm{Br} \mathrm{J}$ Cancer 1993;68:122-4

5. Blann AD, Collum ChN. Circulating endothelial cell/leukocyte adhesion molecules in atherosclerosis. Thromb Haemost 1994;72:151-4.

6. Blann AD, McCollum ChN, Steiner M, Jayson MIV. Circulating adhesion molecules in inflammatory and atherosclerotic vascular disease. Immunol Today $1995 ; 16: 251-2$.

7. Carlos TM, Harlan JM. Leukocyte-endothelial adhesion molecules. Blood 1994:84:2068-101

8. Carson CW, Beall LD, Hunder GG, Johnson CHM, Newman W. Serum ELAM-1 is increased in vasculitis, scleroderma, and systemic lupus erythematosus. J Rheumatol 1993;20:809-14.

9. Czech W, Schopf E, Kapp A. Soluble E-selectin in sera of patients with atopic dermatitis and psoriasis. Correlation with disease activity. $\mathrm{Br} \mathrm{J}$ Dermatol 1996;134:17-21.

10. Eberhard OK, Haubitz M, Brunkhorst FM, Kliem V, Koch KM, Brunkhorst R. Usefulness of procalcitonin for differentiation between activity of systemic autoimmune disease (systemic lupus erythematosus/ systemic antineutrophil cyto- 
plasmic antibody-associated vasculitis) and invasive bacterial infection. ArthritisRheum. 1997;40(7):1250-6.

11. Fischer C, Thiele HG, Hamann A. Lymphocyte-endothelial interactions in inflamed synovia: Involvement of several adhesion molecules and integrin epitopes. Scand J Immunol 1993;38:158-66.

12. Flipo RM, Cardon T, Copin MC, et al. ICAM-1, E-selectin, and TNF alpha expression in labial salivary glands of patients with rheumatoid vasculitis. Ann Rheum Dis 1997;56:41-4.

13. Fuchs D, Weiss G, Wachter H. Neopterin, biochemistry and clinical use as a marker for cellular immune reactions. Int Arch Allergy Immunol 1993;101:1-6.

14. Gearing AJH, Hemingway I, Pigott R, Hughes J, Rees AJ, Cashman SJ. Soluble forms of vascular adhesion molecules, E-Selectin, ICAM-1 and VCAM-1: Pathological significance. Ann N Y Acad Sci 1992;667:324-31.

15. Gearing AJH, Newman W. Circulating adhesion molecules in disease. Immuno Today 1993; 14:506-12.

16. Gorski A. The role of cell adhesion molecules in immunopathology. Immunol Today 1994;15:251-5

17. Horgan KJ, Ginther Luce GE, Tanaka Y et al. Differential expression of VLA-4 and VLA betal discriminates multiple subsets of CD4+CD45RO+ „memory T cells. J Immunol 1992;149:4082-7.

18. Johanessen AC, Cuida M, Halse AK, Jonsson R. Soluble adhesion molecules in saliva and plasma of patients with primary Sjögren's syndrome. Clin Rheumatol 1995; 14:S1,44.

19. Kater L., De Wilde P.C.M. 1992. New developments in Sjögren's syndrome. Cur Opin Immunol 1995;4:657-65.

20. Krejsek J, Slezak R, Kopecky O, Derner V, Andrys C. Elevation of serum soluble intercellular adhesion molecule-1 (sICAM-1) and beta-2-microglobulin in Sjögren's syndrome. Clin Rheumatol 1997;16:149-53.

21. Lez K, Tedder TF. Leukocyte interactions with vascular endothelium. J Immunol 1995; $155: 525-8$.

22. Li JS, Liu MF, Lei HY. Characterization of anti-endothelial cell antibodies in the patients with systemic lupus erythematosus: A potential marker for disease activity. Clin Immunol Immunopathol 1996;97:211-6.

23. Melichar B, Lukeš J, Maliŕ F, Tichý M. Neopterin in the diagnosis of disorder associated with immune system activation. Sb Ved Pr Lek Fak UK Hradec Králové 1993;36:149-55.

24. Moutsopoulos HM, Tzioufas AG. Sjögren's syndrome. In: Klippel JH, Dieppe PA. Rheumatology. Mosby,1994:section 6:27.1-27.12.

25. Nasonov EL, Samsonov MI, Chichasova NV et al. Neopterin : laboratory marke of cellular immunity activation in rheumatoid arthritis (in russian). Ter - Arkh 1998;70(5):28-31.

26. Newman W, Beall LD, Carson CW et al. Soluble E-selectin is found in supernatants of activated endothelial cells and is elevated in the serum of patients with septic shock. J Immunol 1993;150:644-54

27. Picker LJ, Kishimoto TK, Smith CV et al. ELAM-1 is an adhesion molecule fo skin-homing T cells. Nature 1991;349:796-9.

28. Reibnegger G, Egg D, Fuchs D et al. Urinary neopterin reflects clinical activity in patients with rheumatoid arthritis. Arth Rheum 1986;29:1063-70.
29. Reibnegger G, Fuchs D, Fuith LC et al. Neopterin as a marker for activated cellmediated immunity: Application in malignant disease. Cancer Detect Prev 1991:15:383-490

30. Saito I. Possible mechanism of cellular activation and tissue destruction in Sjögren's syndrome. Int. Ophtalm Clinics 1994;34:137-43.

31. Saito I, Tarauch K, Shimuta M et al. Expression of cell adhesion molecules in the salivary and lacrimal gland of Sjögren's syndrome. J Clin Lab Analysis 1993;7:180-7.

32. Seth R, Raymond FD, Makgoba MW. Circulating ICAM-1 isoforms: diagnostic prospects for inflammatory and immune disorders. Lancet 1991;338:83-4.

33. Shimuzu Y, Shaw S, Graber N et al. Activation independent binding of human memory T cells to adhesion molecule ELAM-1. Nature 1991;349:799-802.

34. Spronk PE, Bootsma H, Huitema MG, Limburg PC, Kallenberg CGM. Levels of soluble VCAM-1, soluble ICAM-1, and soluble E-selectin during disease exacerbations in patients with systemic lupus erythematosus (SLE); a long term prospective study. Clin Exp Immunol 1994:97:439-44.

35. St Clair EW. Sjögren's syndrome and autoimmunity. Concepts Immunopathol 1992;8:161-88

36. Sudhoff T, Wehmeier A, Kliche KO et al. Levels of circulating endothelial adhesion molecules (sE-selectin and sVCAM-1) in adult patients with acute leukemia. Leukemia 1996;10:682-6.

37. Verdegaal EME, Beekhuizen H, Blokland I, vanFurth R. Increased adhesion of human monocytes to IL-4 stimulated human venous endothelial cells via CD11/CD18, and very late antigen 4 (VLA-4)/vascular cell adhesion molecule-1 (VCAM-1)-dependent mechanisms. Clin Exp Immunol 1993;93:292-8.

38. Vitali $\mathrm{C}$, Bombardieri S, Haralampos $\mathrm{M}$ et al. Preliminary criteria for the classification of Sjögren's syndrome. Results of a prospective concerted action supported by the European Community. Arthritis Rheum 1993;6:340-7.

39. Wachter H, Fuchs D, Hausen A et al. Neopterin as marker for activation of cellular immunity : immunological basis and clinical applications. Adv Clin Chem 1989;27:81-141.

40. Wahl SM, Feldman GM, McCarthy JB. Regulation of leukocyte adhesion and signaling in inflammation and disease. J Leukoc Biol 1996;59:789-96.

Submitted April 1999.

Accepted July 1999.

RNDr. Ctirad Andrýs,

University Teaching Hospital in Hradec Králové, Department of Clinical Immunology and Allergology, 50005 Hradec Králové, Czech Republic. e-mail: derner@lfhk.cuni.cz. 